УДК 621.774

А.В. Мищенко

Национальная металлургическая академия

Украины, г. Днепр, Украина

\title{
ВОЗМОЖНОСТИ УМЕНЫШЕНИЯ ПОПЕРЕЧНОЙ РАЗНОСТЕННОСТИ ХОЛОДНОКАТАНЫХ ТРУБ ИЗ СПЛАВОВ НА ОСНОВЕ ТИТАНА
}

A.V. Mishchenko

National Metallurgical Academy of Ukraine, Dnipro, Ukraine

\section{POSSIBILITIES FOR REDUCING LATERAL DIFFERENCE COLD ROLLED TITANIUM ALLOY PIPE}

Цель. Целью исследований маршрутов производства и твердости труб было получение новых научно-практических данных о возможности уменьшения поперечной разностенности холоднокатанных труб из сплавов на основе титана для дальнейших рекомендации о модернизации маршрутов прокатки труб.

Методика. Исследованы и обобщены данные, характеризующие химический состав и механические свойства труб, изготовленных из различных сплавов на основе титана. Для труб из сплава ПТ-1М проведен эксперимент по исследованию твердости, что дополнило ранее обобщенные данные о сплавах. Исследование твердости труб выполнялось путем лабораторных исследований образиов труб различной толщины из сплава ПТ-1М в недеформированном состоянии. Для построения графика соотношение предела прочности $\sigma_{\mathrm{B}}$ и твердости НВ сплавов на основе титана были использованы как табличные показатели, так и результаты собственных исследований. Исследование проектирования маршрутов прокатки труб из сплавов на основе титана выполнялось путем сопоставления рассчитанных параметров в соответствии с необходимыми технологическими прочедурами.

Результаты. Исследовано соотношение предела прочности $\sigma_{\mathrm{B}}$ и твердости $\mathrm{HB}$, а также построен график соотношения для сплавов на основе титана, который включает данные о таких сплавах как ВT1-00, ПТ-7М, АТЗ и ПТ-1М, ОТ4-0, ВТ9 и др. Теоретически и экспериментально показано, что абсолютная разностенность стенки холоднокатаных труб из сплавов на основе титана обратно пропориионально зависит от степени относительной деформации при холодной прокатке. Рассмотрены подходы, применяемые для проектирования маршрутов прокатки труб из сплавов на основе титана. Проведено сравнение известного маршрута прокатки, а такэе новых разработанных маршрутов прокатки. Прогнозирование изменения разностенности с использованием развитого метода показало, что у новых маршрутов прогнозируемый уровень разностенности ниже на $30 \%$ в сравнении с существующим.

Научная новизна. Дополнены данные о твердости труб, изготавливаемых их сплава ПТ-1М. Расширены сведения зависимости твердости труб от предела прочности для группы титановых сплавов. Показано практическое применение предложенного метода прогнозирования поперечной разностенности.

Практическая ценность. По результатам исследований рекомендованы подходы к выбору и разработке маршрутов прокатки при производстве холоднокатаных труб из сплавов на основе титана, обеспечиваюших повышение их точности. Представлены формулы, пригодные для экспресспрогноза точности труб в зависимости от степени суммарной деформации при холодной прокатке.

Ключевые слова: трубы, титан, сплавы, химический состав, механические свойства, технология, прокатка, режимы.

DOI: $10.34185 / 0543-5749.2019-5-6-57-66$

(C) Мищенко А.В., 2019 
На нынешнем этапе развития технологии производства холоднокатаных труб из сплавов на основе титана одна из основных научнотехнических задач состоит в разработке способов уменьшения их поперечной разностенности. Сложность решения этой задачи заключается в том, что существенную поперечную разностенность имеет и горячекатаная, и горячепрессованная заготовка из титановых сплавов, поступающая на станы холодной прокатки труб (ХПТ). Теоретическая проработка в строгой постановке вопроса изменения разнотолщинности стенки труб в функции степени деформации при холодной прокатке на этих станах сопряжена со значительными трудностями. В первую очередь возникают сложности с определением типа разностенности - симметричная или эксцентрическая.

Если в поперечном сечении трубы максимальное значение толщины стенки располагается напротив ее минимального значения, то такую разностенность, как правило, относят к эксцентрическому типу (рис. 1). При этом минимальное и максимальное значения толщины стенки трубы могут располагаться в выпусках калибров (рис. 1, а), по вершинам ручья калибров (рис. 1, б) или как-либо иначе. Трудности теоретического анализа обусловлены сложностью расчетов величин обжатий в очаге деформации участков утолщенной и утоненной стенки трубы (рис. 2), различным упрочнением металла в этих зонах и т.д. Попытка учета всех влияющих факторов требует настолько значительного усложнения задачи, что теряется целесообразность ее решения. Поэтому для выявления качественных закономерностей изменения поперечной разностенности труб из сплавов на основе титана при их холодной прокатке на станах ХПТ допустимо и целесообразно использование подходов, основанных на экспериментальных и полученных теоретически при принятии обоснованных допущений результатах.

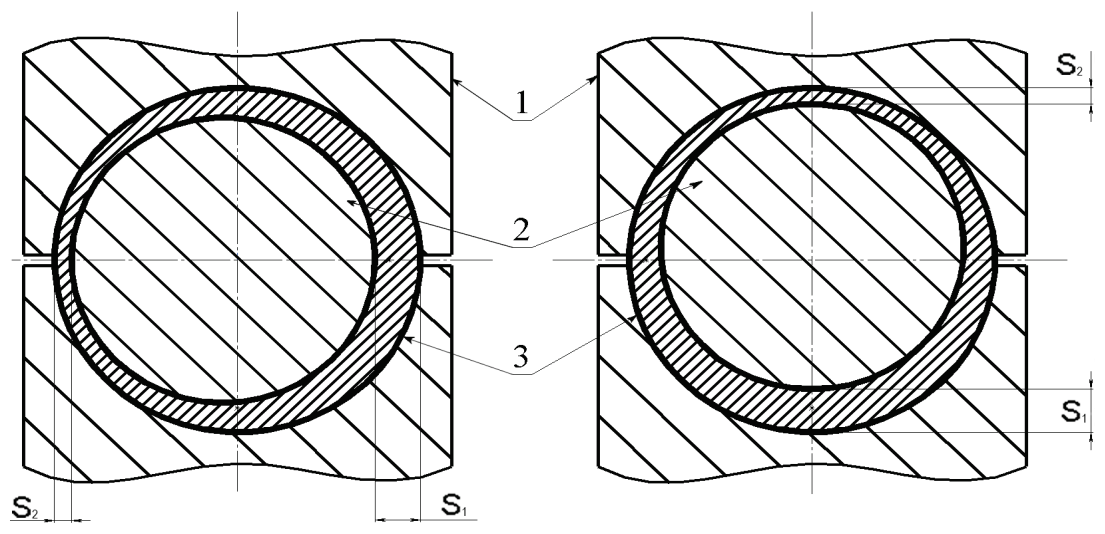

Рис. 1. Схема очага деформации, в поперечном сечении прокатываемых на станах ХПТ труб с эксцентрической разностенностью: 1 - калибры; 2 - оправка; 3 - труба; $\mathrm{S}_{1}$ - толщина стенки трубы в зоне максимального утолщения; $S_{2}$ - в зоне минимальной толщины; а - разностенность в выпусках; б - разностенность по вершинам ручья калибров.

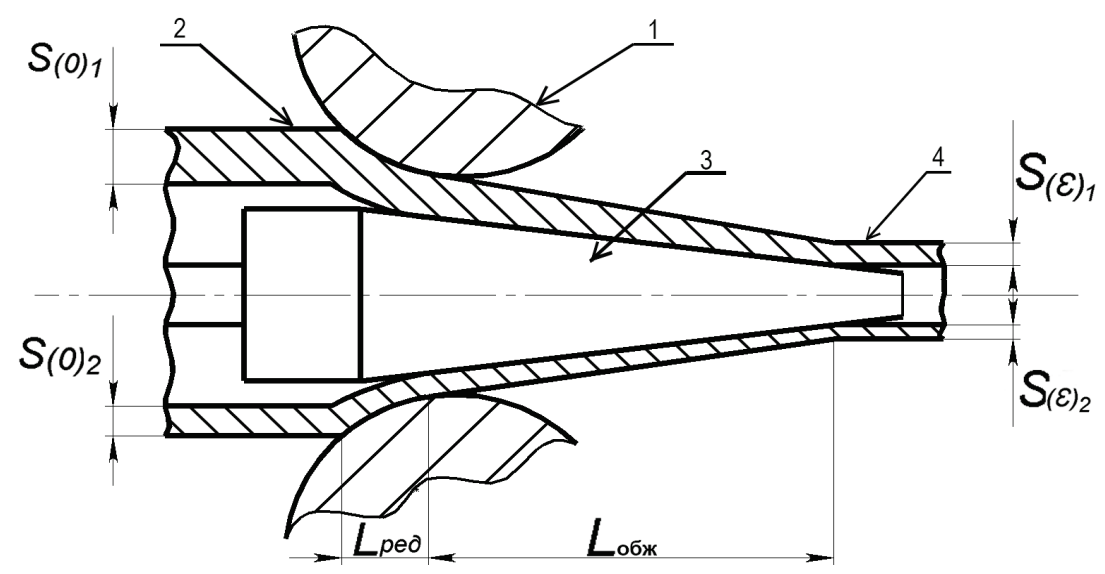

Рис. 2. Схема очага деформации в сечение вдоль оси прокатки по гребню калибров: 1 - калибры; 2 труба-заготовка, 3 - оправка, 4 - готовая труба; $\mathrm{S}_{1}(0)$ - толщина стенки исходной трубы-заготовки в зоне максимального утолщения; $S_{2}(0)$ - толщина стенки трубы-заготовки в зоне минимальной толщины, $S_{1}(\varepsilon)$ - толщина стенки прокатанной трубы в зоне максимального утолщения; $S_{2}(\varepsilon)$ - в зоне минимальной толщины стенки, $L_{\text {ред }}-$ длинна зоны редуцирования, $L_{\text {обж }}-$ длина обжимной зоны 
Трубы из сплавов на основе титана прокатывают на станах ХПТ с минимально возможным редуцированием в очаге деформации из-за склонности этих сплавов к трещинообразованию и высоких требований к качеству внутренней поверхности. Уменьшение разностенности исходной заготовки возможно в основном за счет утонения стенки прокатываемой трубы в процессе обжатия на оправке. При экспериментальных исследованиях прокатки на стане ХПТ разностенной заготовки очаг деформации можно рассматривать упрощенно как сжатие валками (калибрами) слоев металла разнотолщинной стенки трубы на жесткой оправке. Такую модель очага деформации применяли авторы работ [1-5 и др.] при исследовании разностенности холоднокатаных труб. В частности, процесс прокатки разностенной трубы в калибрах представляли в виде совместной осадки образцов металла разной толщины (рис. 3).

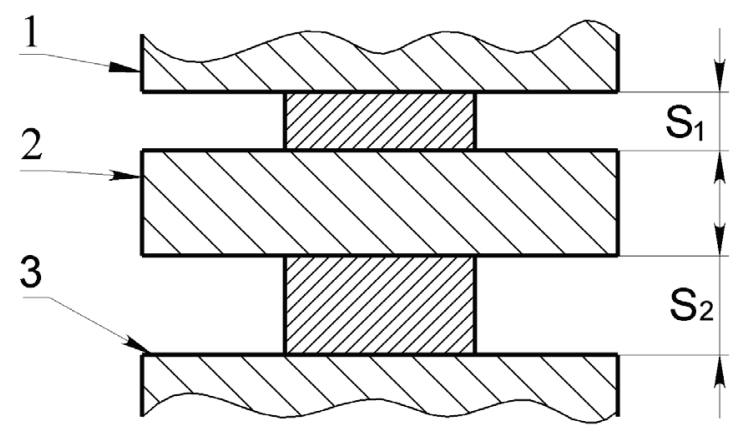

Рис. 3. Схема осадки (пластического деформирования) бойками двух образцов металла различной толщины, разделенных между собой жесткой недеформируемой плитой. Обозначено: 1 - верхний и нижний бойки, имитирующие калибры стана ХПТ; 2 - жесткая плита, имитирующая оправку; $\mathrm{S}_{1}$ и $\mathrm{S}_{2}$ - образцы большей и меньшей толщин, имитирующие стенку трубы в зонах утолщения и утонения

Согласно схемам на рис. 2 и рис. 3 обозначаем $S_{2}$ - толщина стенки трубы в зоне утолщения (образец большей толщины); $S_{1}$ - в зоне утонения (образец меньшей толщины). Соответственно абсолютные деформации при пластическом сжатии будут: $\Delta \mathrm{S}_{1}$ - сравнительно тонкого образца; $\Delta \mathrm{S}_{2}$ - сравнительно толстого образца; относительные деформации - $\varepsilon_{1}=\Delta \mathrm{S}_{1} / \mathrm{S}_{1}$ и $\varepsilon_{2}=\Delta \mathrm{S}_{2} / \mathrm{S}_{2}$. При этом $\Delta \mathrm{S}_{1}=\mathrm{S}_{1}(0)-\mathrm{S}_{1}\left(\varepsilon_{1}\right)$ и $\Delta \mathrm{S}_{2}=\mathrm{S}_{2}(0)-\mathrm{S}_{2}\left(\varepsilon_{2}\right)$, где $\mathrm{S}(0)$ - толщина образца в исходном состоянии и $\mathrm{S}(\varepsilon)$ - толщина после пластического сжатия образца со степенью деформации $\varepsilon$. Абсолютная исходная разностенность заготовки в поперечном сечении равна
$R_{\text {абс }}(0)=\mathrm{S}_{2}(0)-S_{1}(0)$. Относительная разностенность $\mathrm{R}_{\text {отн }}(0)=\frac{\mathrm{S}_{2}(0)-\mathrm{S}_{1}(0)}{\mathrm{S}_{2}(0)}$. В знаменателе выражения $R_{\text {отн }}$ можно поставить номинальную (указанную в документации) толщину стенки заготовки или среднее значение толщины стенки $\mathrm{S}_{\mathrm{cp}}(0)=\frac{\mathrm{S}_{1}(0)+\mathrm{S}_{2}(0)}{2}$. Это не имеет принципиального значения для рассматриваемой задачи. Аналогичные обозначения $R_{\text {абс }}(\varepsilon)$ и $R_{\text {отн }}(\varepsilon)$ вводим для оценки разностенности труб, прокатанных с суммарной степенью деформации $\varepsilon, \%$. Причем, $\varepsilon=\frac{S(0)-S(\varepsilon)}{S(0)} \cdot 100 \%=\left[1-\frac{S(\varepsilon)}{S(0)}\right] \cdot 100 \%$.

Закономерность процесса холодной прокатки на станах ХПТ разностенной заготовки (трубы) в случае, когда зоны с утолщенной и утоненной стенкой расположены по гребням верхнего и нижнего калибров, состоит в том, что вследствие одинаковой силы, действующей в вертикальном сечении очага деформации величина абсолютного обжатия $\Delta \mathrm{S}_{1}$ утолщенного участка стенки больше, чем $\Delta \mathrm{S}_{2}$ утоненного. Эксцентрическая поперечная разностенность трубы при прокатке уменьшается. Но вследствие разных $\Delta \mathrm{S}_{1}$ и $\Delta \mathrm{S}_{2}$ неодинаковыми оказываются величины относительных деформаций $\varepsilon_{1}$ и $\varepsilon_{2}$ и, как результат, значения сопротивления деформации $\sigma_{1}\left(\varepsilon_{1}\right)$ и $\sigma_{2}\left(\varepsilon_{2}\right)$ прокатываемого металла из-за разного его упрочнения в утолщенных и утоненных зонах стенки трубы.

В фундаментальной монографии А.В. Третьякова, В.И. Зюзина [6] обобщена информация о значениях механических свойств ряда титановых сплавов, подвергаемых обработке давлением. Анализируя приведенные в этой книге данные, отметим, что на свойства титановых сплавов влияет в основном содержание следующих элементов: Al, Cr, V, Mo, Mn. Именно эти элементы используются в промышленности для изменения структуры и свойств сплавов на основе титана. Судя по данным табл. 1, в составах рассмотренных сплавов содержание элементов $\mathrm{C}, \mathrm{O}, \mathrm{N}, \mathrm{H}, \mathrm{Fe}, \mathrm{Si}$ разное. Так, содержание азота во всех сплавах должно быть в пределах $0,04-$ $0,05 \%$, углерода не более $0,1 \%$ и не более $0,05 \%$ для сплавов ВТ1-00, ВТ1-0 и ПТ-1М. Содержание водорода в большинстве титановых сплавов должно находиться на уровне $0,01-$ $0,015 \%$. В сплавах ВТ1-00, ПТ-7М, АТ3 и ПТ$1 \mathrm{M} \mathrm{в} \mathrm{диапазоне} \mathrm{0,006-0,008 \% .} \mathrm{Доля} \mathrm{кислорода} \mathrm{в}$ сплавах не должна превышать $0,15-0,3 \%$. В сплавах ВТ1-00, ПТ-1М не более $0,1-0,12 \%$. Достаточно жесткие требования к содержанию примесей в указанных сплавах обусловлены тем, что изготавливаемые из них детали применяют- 
ся, в основном, в ответственном энергетическом оборудовании. Трубы из титановых сплавов работают в агрессивных средах и, соответственно, к ним предъявляются высокие требования по надёжности.

Соотношение твердости НВ и предела прочности $\sigma_{\mathrm{B}}$ представляет научный интерес, так как может использоваться в виде экспресс теста свойств материала. На рис. 4 представлена зависимость твёрдости НВ титановых сплавов от их предела прочности $\sigma_{B}$, построенная по данным таблицы 1. Уравнение регрессии, опи- сывающая эту зависимость имеет вид $\mathrm{HB}=0,73 \sigma_{\mathrm{B}}{ }^{0,89}, \mathrm{R}^{2}$ равен 0,74. Учёт твёрдости сплава и её изменений при пластической деформации позволяет улучшить прогноз механических свойств и точности прокатываемых труб в производственных условиях. В литературных источниках нет информации об уровне твердости труб из титанового сплава марки ПТ-1М. В результате выполненных автором данной статьи исследований установлено, что твердость труб из сплава ПТ-1М в недеформированном состоянии составляет 120-150 НВ.

Таблица 1. Химический состав (содержание элементов, \%) и механические свойства $\left(\sigma_{\mathrm{B}}, \mathrm{H} / \mathrm{Mм}^{2} ; \delta, \%, \mathrm{HB}\right)$ сплавов на основе титана $[6,7$ и др.]

\begin{tabular}{|c|c|c|c|c|c|c|c|c|c|}
\hline Сплав & $\sigma_{\mathrm{B}}$ & $\delta$ & $\mathrm{HB}$ & $\mathrm{Al}$ & $\mathrm{V}$ & $\mathrm{Mo}$ & $\mathrm{Zr}$ & $\mathrm{Si}$ & $\mathrm{Fe}$ \\
\hline ВТ1-00 & $300-450$ & 20 & $116-143$ & - & - & - & - & 0,08 & 0,15 \\
\hline ВТ1-0 & $400-450$ & 15 & $131-163$ & - & - & - & - & 0,1 & 0,25 \\
\hline ВТ1-2 & $590-930$ & 8 & $\mathrm{H} /$ д & - & - & - & - & 0,15 & 1,5 \\
\hline ОТ4-0 & $490-637$ & 15 & $156-207$ & $0,4-1,4$ & - & - & 0,3 & 0,12 & 0,3 \\
\hline ОТ4-1 & $540-735$ & 20 & $197-255$ & $1,5-2.5$ & - & - & 0,3 & 0,12 & 0,3 \\
\hline ОТ4 & $635-885$ & $10-12$ & $207-285$ & $3,5-5,0$ & - & - & 0,3 & 0,12 & 0,3 \\
\hline ВТ5 & $685-735$ & $10-14$ & $229-321$ & $4,5-6,2$ & 1,2 & 0,8 & 0,3 & 0,12 & 0,3 \\
\hline ВТ6 & $835-885$ & $8-20$ & $293-361$ & $5,3-6,8$ & $3,5-5,3$ & - & 0,3 & 0,1 & 0,6 \\
\hline ВТбс & $755-935$ & 12 & $241-321$ & $5,3-6,5$ & $3,5-4,5$ & - & 0,3 & 0,15 & 0,25 \\
\hline ВТ3-1 & 930 & 12 & $269-363$ & $5,5-7,0$ & - & $2,0-3,0$ & 0,5 & $0,15-0,40$ & $0.2-0,7$ \\
\hline ВТ8 & $930-980$ & $6-8$ & $269-363$ & $5,8-7,0$ & - & $2,8-3,8$ & 0,5 & $0,20-0,40$ & 0,3 \\
\hline ВТ9 & $930-980$ & $8-14$ & $269-363$ & $5,8-7,0$ & - & $2,8-3,8$ & $1.0-2,0$ & $0,20-0,5$ & 0,25 \\
\hline ВТІ4 & $865-1080$ & $8-10$ & $255-341$ & $3,5-6,3$ & $0,9-1,9$ & $2,5-3,8$ & 0,3 & 0,15 & 0,25 \\
\hline ВТ20 & 885 & 10 & $255-341$ & $5,5-7,0$ & $0,8-2,5$ & $0,5-2,0$ & $1,5-2,5$ & 0,15 & 0,25 \\
\hline ВТ22 & 1100 & 10 & $285-388$ & $4,4 \sim 5,7$ & $4,0-5,5$ & $4.0-5,5$ & 0,3 & 0,15 & $0-5-1.5$ \\
\hline ПТ-7М & $480-680$ & $15-25$ & н/д & $1,8-2,5$ & - & & $2,0-3,0$ & 0,12 & 0,25 \\
\hline АТ3 & 590 & 15 & н/д & $2,0-3,5$ & & - & - & $0,20-0,40$ & $0,2-0,5$ \\
\hline ПТ-1М & $343-568$ & 27 & $120-150$ & $0,2-0,7$ & - & - & 0,3 & 0,1 & 0,2 \\
\hline
\end{tabular}

Примечание: н/д - нет данных.

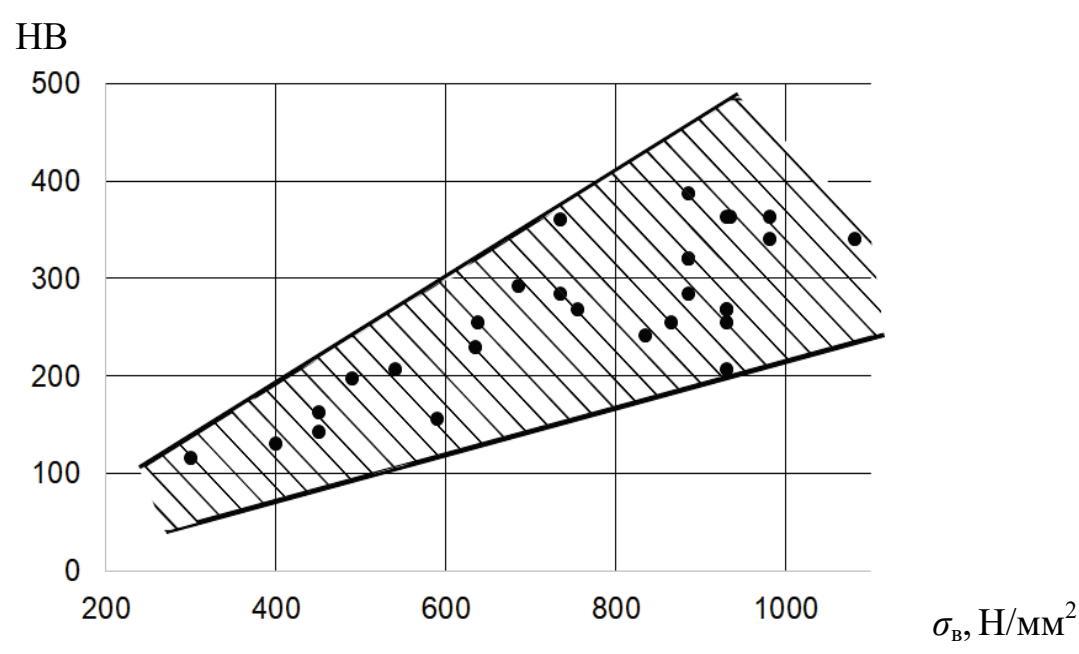

Рис. 4. Соотношение предела прочности $\sigma_{\mathrm{B}}$ и твердости НВ сплавов на основе титана 
Зависимости условного предела текучести $\sigma_{0,2}$, временного сопротивления $\sigma_{B}$ от степени деформации $\varepsilon$ представлены в монографии [6, с. 174-179] графиками и зависимостями в виде $\sigma(\varepsilon)=\sigma(0)+a \varepsilon^{n}$, где $\sigma(0)$ и $\sigma(\varepsilon)$ предел текучести или прочности сплава в исходном состоянии и после деформации; $\varepsilon$ - степень деформации, \%; $a$ - коэффициент; $n$ - показатель степени. Для группы, состоящей из ряда титановых сплавов (титан технический; ВТ1-1; ВТ1-2; ВТ4; ВТ5; ВТ6; ОТ4; ИМП-1А; ИМП-7), предложенная в $[6$, с. 188] эмпирическая формула в наших обозначениях имеет вид:

$$
\sigma_{B}(\varepsilon)=\sigma_{B}(0)+2,4 \varepsilon^{0,63} .
$$

Размерность $\sigma_{B}$ - кгс/мм², а степень относительной деформации $\varepsilon$ выражена в \%. Заметим, что в проводимом анализе размерность этих величин не имеет принципиального значения. В указанной обобщенной формуле коэффициент $a=2,4$, показатель степени $n=0,63$. Согласно приведенным в монографии [6, с. 174-179] данным для разных титановых сплавов указанные коэффициент и показатель упрочнения имеют широкий интервал значений $a=1,6-2,2$, показатель $n=0,68-0,73$.

Наибольшее распространение при расчетах величины $p$ среднего значения нормальных контактных напряжений (удельных давлений) в очаге деформации при холодной прокатке труб на станах ХПТ получила формула Ю.Ф. Шевакина [8, с.93]:

$$
p=\sigma_{\mathrm{B}}\left[n_{\omega}+f\left(\frac{S(0)}{S(\varepsilon)}-1\right) \frac{R_{\mathrm{rp}}}{R_{m}} \cdot \frac{\sqrt{2 R_{\mathrm{rp}} \Delta S}}{S(\varepsilon)}\right],
$$

где $\sigma_{B}$ - предел прочности; $n_{\omega}$ - коэффициент, учитывающий влияние среднего главного напряжения $\left(n_{\omega}=1,02-1,08\right) ; f$ - коэффициент трения на поверхности контакта инструмент-

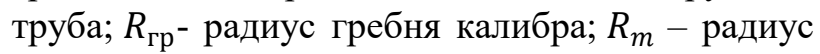
ведущей шестерни клети стана ХПТ.

Формула Ю.Ф. Шевакина пригодна для расчетов $p$. Однако из-за громоздкости ее применение усложняет выкладки при изучении закономерностей изменения разностенности труб в процессе холодной прокатки. При упрощенном подходе к исследованию трансформации разностенности труб, как уже отмечено выше, допустимо процесс их холодной прокатки рассматривать как совместную осадку двух образцов металла разной толщины, разделенных жесткой пластиной (рис. 3). Оценивая характер изменения удельной силы сжатия $p(\varepsilon)$ при пластическом деформировании плоских образцов разной толщины, в первом приближении принимаем, что $p(\varepsilon) \approx \sigma_{T}(\varepsilon)$ или $p(\varepsilon) \approx \sigma_{B}(\varepsilon)$. То есть, пренебрегаем влиянием сил трения на поверхностях контакта рабочего инструмента с деформируемым металлом (рис. 2). Упрощаем формулу (1) Ю.Ф. Шевакина, полагая выражение в квадратных скобках равным единице. Тогда, при одной и той же силе прокатки и удельном давлении, в очаге деформации, обжатие стенки трубы в зонах ее утолщения и утонения будет разным. Соответственно различным будет и упрочнение металла в этих зонах. Принимая допущение $p(\varepsilon)=\sigma(\varepsilon)$ запишем

и

$$
\begin{aligned}
& p\left(\varepsilon_{1}\right)=\sigma\left(\varepsilon_{1}\right)=\sigma(0)+a \varepsilon_{1}^{n} \\
& p\left(\varepsilon_{2}\right)=\sigma\left(\varepsilon_{2}\right)=\sigma(0)+a \varepsilon_{2}^{n} .
\end{aligned}
$$

Но поскольку при прокатке разностенной трубы (рис. 1), как и при моделировании этого процесса осадкой бойками, имитирующими калибры стана ХПТ, двух подвергаемых пластической деформации прямоугольных образцов металла, разделенных жесткой пластиной, имитирующей оправку стана ХПТ (рис. 3), сила прокатки (осадки) одинакова, то $p\left(\varepsilon_{1}\right)=p\left(\varepsilon_{2}\right)=p(\varepsilon)$. Для выполнения этого условия должно быть $\varepsilon_{1}=\varepsilon_{2}$.

Таким образом, упрощение формулы (1) Ю.Ф. Шевакина принятием выражения в квадратных скобках равным единице, в рассматриваемой задаче равнозначно допущению, что относительная деформация $\varepsilon_{1}$ и $\varepsilon_{2}$ утолщенных и утоненных участков стенки трубы одинакова.

Допуски по толщине стенки (разностенность) трубной заготовки из титановых сплавов улучшенного качества по ГОСТ 21945-76 не превышает $\pm 12,5 \%$. Согласно требованиям стандарта ASTM B338 к холоднокатаным трубам из титановых сплавов допуск на отклонения толщины стенки составляет $\pm 10 \%$. Эти величины не являются значительными и позволяют в упрощенном анализе рассматриваемой задачи принимать $\varepsilon_{1}=\varepsilon_{2}=\varepsilon$, где $\varepsilon$ - номинальная величина (среднее значение) суммарной относительной деформации стенки трубы при холодной прокатке.

Используя зависимость $\sigma(\varepsilon)$ и выражения $S(0)$ и $S(\varepsilon)$, запишем

$$
\begin{aligned}
p(\varepsilon) & \approx \sigma(\varepsilon)=\sigma(0)+a \varepsilon^{n}= \\
& =\sigma(0)+a\left[1-\frac{S(\varepsilon)}{S(0)}\right]^{n} .
\end{aligned}
$$

Решая уравнение (2) относительно $S(\varepsilon)$, получим:

$$
S(\varepsilon)=S(0)\left[1-\sqrt[n]{\frac{\sigma(\varepsilon)-\sigma(0)}{a}}\right] .
$$


Применительно к сжатию тонкого образца (рис. 3) в формуле (3) должны фигурировать $S_{1}(0)$ и $S_{1}(\varepsilon)$. Толстого $S_{2}(0)$ и $S_{2}(\varepsilon)$. Поскольку $R_{\text {абс }}=S_{2}-S_{1}$, то, используя формулу (3), выразим связь $R_{\text {абс }}(\varepsilon)$ абсолютной разностенности $R_{\text {абсс }}(\varepsilon)=S_{1}(\varepsilon)-S_{2}(\varepsilon)$ трубы после прокатки или абсолютной разнотолщинности деформируемых сжатием (рис. 2) плоских образцов с абсолютной разностенностью исходной трубной заготовки $R_{\text {абсс }}(0)$ или исходной толщиной образцов. Получим:

$$
\begin{gathered}
R_{\text {абс }}(\varepsilon)=S_{1}(\varepsilon)-S_{2}(\varepsilon)= \\
=\left(S_{1}(0)-S_{2}(0)\right)\left[1-\sqrt[n]{\frac{\sigma(\varepsilon)-\sigma(0)}{a}}\right] .
\end{gathered}
$$

Поскольку $R_{\text {аб̆с }}(0)$ показатель разностенности исходной трубной заготовки или показатель различия толщин деформируемых образцов (рис.3) равен разности $S_{1}(0)-S_{2}(0)$, то

$$
R_{\text {абс }}(\varepsilon)=\left[1-\sqrt[n]{\frac{\sigma(\varepsilon)-\sigma(0)}{a}}\right] R_{\text {абс }}(0) .
$$

Как видим, в формуле (5) соблюдается условие, что $\sigma(\varepsilon)=\sigma(0)$ и $R_{\text {абс }}(\varepsilon)=R_{\text {абс }}(0)$ при $\varepsilon=0$. Подставив в формулу (5) зависимость $\sigma(\varepsilon)=\sigma(0)+a \varepsilon^{n}$, получим

$$
R_{\text {абс }}(\varepsilon)=[1-\varepsilon] R_{\text {абс }}(0) .
$$

Таким образом, согласно выражению (6) в первом приближении можно считать, что абсолютная разностенность холоднокатаных труб линейно (обратно пропорционально) зависит от степени деформации $\varepsilon$ при прокатке. В формуле (6) степень деформации выражена в относительных величинах, $\varepsilon=\Delta S / S$.

Получить зависимость (6) позволило пренебрежение влиянием трения на поверхности контакта деформирующего инструмента (плит на рис. 3) и пластически деформируемого металла при осадке и принятие равенства величин нормального контактного напряжения (удельного давления) $p$ в очаге деформации сопротивлению деформации металла $\sigma$, т. е. принятие $p=\sigma$. Такое упрощение решения равноценно принятию условия, что коэффициент напряженного состояния в очаге деформации равен единице. Насколько принятые допущения вносят погрешность в полученное решение (6) оценим теоретически и экспериментально.

Согласно данным, приведенным в монографии [7, с. 59-60], при осадке силы трения, действующие на поверхности контакта деформируемого металла с рабочим инструментом (бойками), повышают силу сжатия $p$ по сравнению с сопротивлением деформации металла $\sigma$ на $10-$ $15 \%$. Зависимость среднего удельного давления $p$ в очаге деформации при осадке цилиндрических образцов от истинного сопротивления деформации металла $\sigma$ можно выразить формулой С.И. Губкина [7, с.60]

$$
\sigma=p /\left(1+\frac{1}{3} f \frac{d}{h}\right)
$$

или

$$
p=\sigma\left(1+\frac{1}{3} f \frac{d}{h}\right)
$$

где $d$ и $h$ - текущие диаметры и высоты (толщины) деформируемых образцов; $f$ - коэффициент трения на поверхности контакта деформируемого металла с рабочим инструментом (бойками).

Заметим, что формула (8) по своей структуpe подобна формуле (1) Ю.Ф. Шевакина. При пренебрежении влияния трения, т.е. при $f=0$, формулы (7) и (8) преобразуются в равенство $\sigma=p$, которое было принято при выводе формулы (6).

В промышленных условиях при холодной прокатке на станах ХПТ труб из сплавов на основе титана в очаг деформации подается технологическая смазка как на калибры, так и на оправку. Коэффициент трения $f$ в очаге деформации при холодной прокатке на оправке находится в пределах 0,04-0,08. Следовательно, вторые слагаемые в скобках в формулах (7) и (8) много меньше единицы, а значит, принятие условия, что $p \approx \sigma$ вполне допустимо в оценочных расчетах.

Влияние степени деформации при холодной прокатке труб на изменение их разностенности экспериментально исследовали, моделировали путем одновременной осадки бойками двух плоских образцов размерами $10 \mathrm{x} 40$ мм толщинами $S_{\max }=8,5$ мм и $S_{\min }=7,0$ мм из титанового сплава ПТ-1М, разделенных недеформируемой пластиной (рис. 3). Деформирующим инструментом (бойками и промежуточной жесткой пластиной) служили три плиты из стали 60ХФА. В этом эксперименте моделировали изменение разностенности труб из сплавов на основе титана при холодной прокатке на стане ХПТ-75 по маршруту 63 x 8,5 мм $\rightarrow 38$ x 4,5 мм. Образцы осаживали прерывисто (дробно) с интервалом абсолютных обжатий через 1,0 мм. Суммарная относительная деформация составила $\sim 60 \%$. В относительных единицах $\varepsilon \approx 0,6$. Методика экспериментов подробно изложена в нашей работе [4].

Результаты экспериментов показали (рис. 5), что вследствие осадки образцов указанных размеров их абсолютная разнотолщинность уменьшилась в $\sim 3$ раза с 1,5 мм до 0,49 мм, относительная разнотолщинность с 17,6 \% до $14 \%$. 

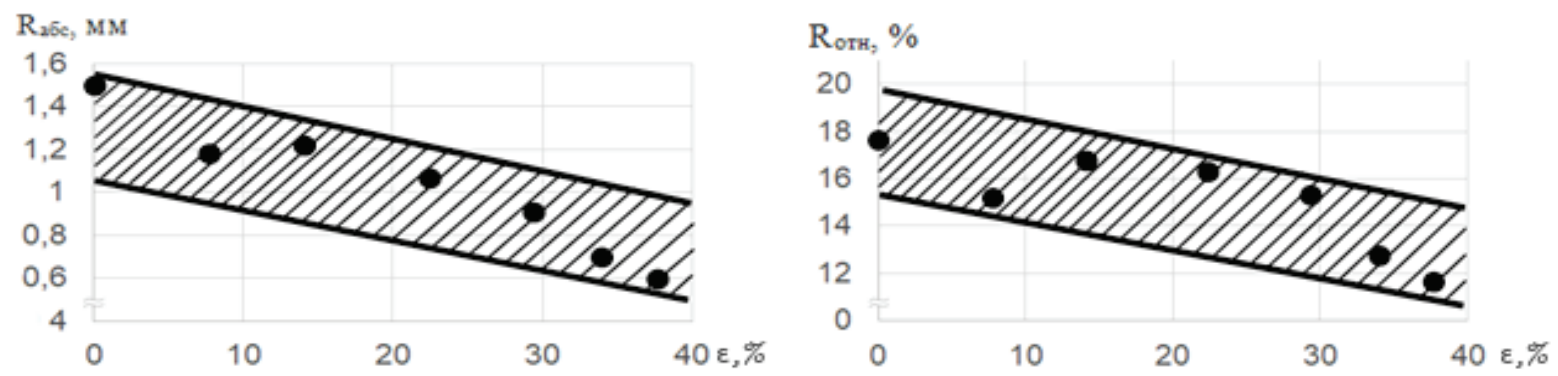

Рис. 5. Экспериментально установленные зависимости изменения разнотолщинности образцов из титанового сплава ПТ-1М от степени деформации $(\mathcal{E}, \%)$ при осадке (условия экспериментов указаны в тексте)

Представленные на рис. 5 данные аппроксимировали экспоненциальными зависимостями. Получили следующие зависимости $R_{\text {абс }}$ мм и $R_{\text {отн }}, \%$ от относительной степени суммарной деформации $\varepsilon_{\Sigma}, \%$ :

и

$$
R_{\text {абс }}=1.5 e^{-0.018 \varepsilon_{\Sigma}}
$$

$$
R_{\text {отн }}=17.6 e^{-0.007 \varepsilon_{\Sigma}} .
$$

Величины корреляционных отношений составляют 0,96 для абсолютной и 0,78 для относительной разнотолщинности, что говорит о статистической значимости полученных зависимостей. При аппроксимации массивов полученных величин (рис. 5) линейной или степенной зависимостями значения корреляционного отношения оказываются меньшими.

Расчеты по формуле (6) абсолютной разнотолщинности указанных образцов после осадки со степенью деформации $60 \%$ показали, что $R_{\text {абс }}=1,5(1-0,6)=0,9$ мм. То есть, расчеты по формуле (6), как и ожидалось, показали несколько завышенные результаты относительно реального уменьшения разностенности до (0,4 мм), поскольку при выводе формулы (6) пренебрегали влиянием трения на контактных поверхностях инструмента и деформируемого металла, полагали $f=0$ в формулах (1), (7) и (8). При расчетах по формуле (8) $R_{\text {абс }}=0,528$ мм. Расхождение результатов расчетов с экспериментальными данными составляло $\sim 7 \%$. Формулы (9) обеспечивают лучший прогноз, чем формула (6). Причины несовпадения расчетных и экспериментальных результатов состоят в следующем.

Площадь контактной поверхности осаживаемых образцов до начала деформации была

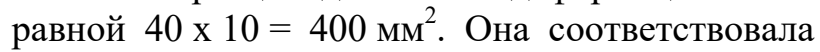
площади круга диаметром $d \approx 22,6$ мм. При толщине образца $h=8,5$ мм и коэффициенте трения $f=0,08$ второй член в скобках в формулах (7) и (8) равен $\frac{1}{3} f \frac{d}{h} \approx 0,07$. И, соответственно, $p \approx 1,07 \sigma$. Коэффициент 1,07 перед значени- ем сопротивления деформации ориентировочно показывает порядок погрешности, внесенной допущениями, принятыми при использовании формул (7) и (8) применительно к рассматриваемым условиям экспериментов. Погрешность, внесенная допущениями в формулу (1) больше, поскольку очаг деформации и сам процесс прокатки труб на станах ХПТ значительно сложнее, чем процесс осадки. Тем не менее результаты экспериментов свидетельствуют, что формула (6) вполне пригодна для экспресс-анализа изменения разностенности труб в функции степени деформации при холодной прокатке.

Рассмотрим на практических примерах возможности использования полученных формул (9). Для этого сравним различные маршруты производства труб из сплавов на основе титана (рис. 6). Прогноз уровня разностенности труб выполним путем расчета по полученным формулам. Маршруты (рис. 6) разработаны для сплава ПТ-1М, но могут быть использованы также при прокатке труб из других сплавов, $\sigma_{\mathrm{B}}$ которых в исходном состоянии не превышает $500-$ $600 \mathrm{H} / \mathrm{мm}^{2}$. Основное различие приведенных на рис. 6 маршрутов состоит в использовании для прокатки труб заготовки разных размеров. Использование заготовки нескольких размеров позволяет уменьшить количество комплектов калибров и оправок, снизить расход металла на изготовление готовых труб, сократить производственный цикл производства труб со всеми вытекающими из этого позитивными эффектами.

Сравнивая маршруты производства холоднокатаных труб по предлагаемой (A) и известной технологии (Б) отметим, в первую очередь, что предлагаемые маршруты разделены на три основных варианта, предусматривающие использование заготовки разных размеров. Такая технология позволяет снизить расходный коэффициент металла (РКМ) при производстве труб нестандартных размеров, например, 76 х 3 мм за счёт применения всего только двух прокаток с 
равномерно распределенными обжатиями. Производство таких труб по общепринятой технологии из заготовки $127 \times 16$ мм сопровождается применением маршрутов, предусматривающих многоразовую прокатку на различных станах со сравнительно большими деформациями стенки, что негативно сказывается на точности и механических свойствах труб.

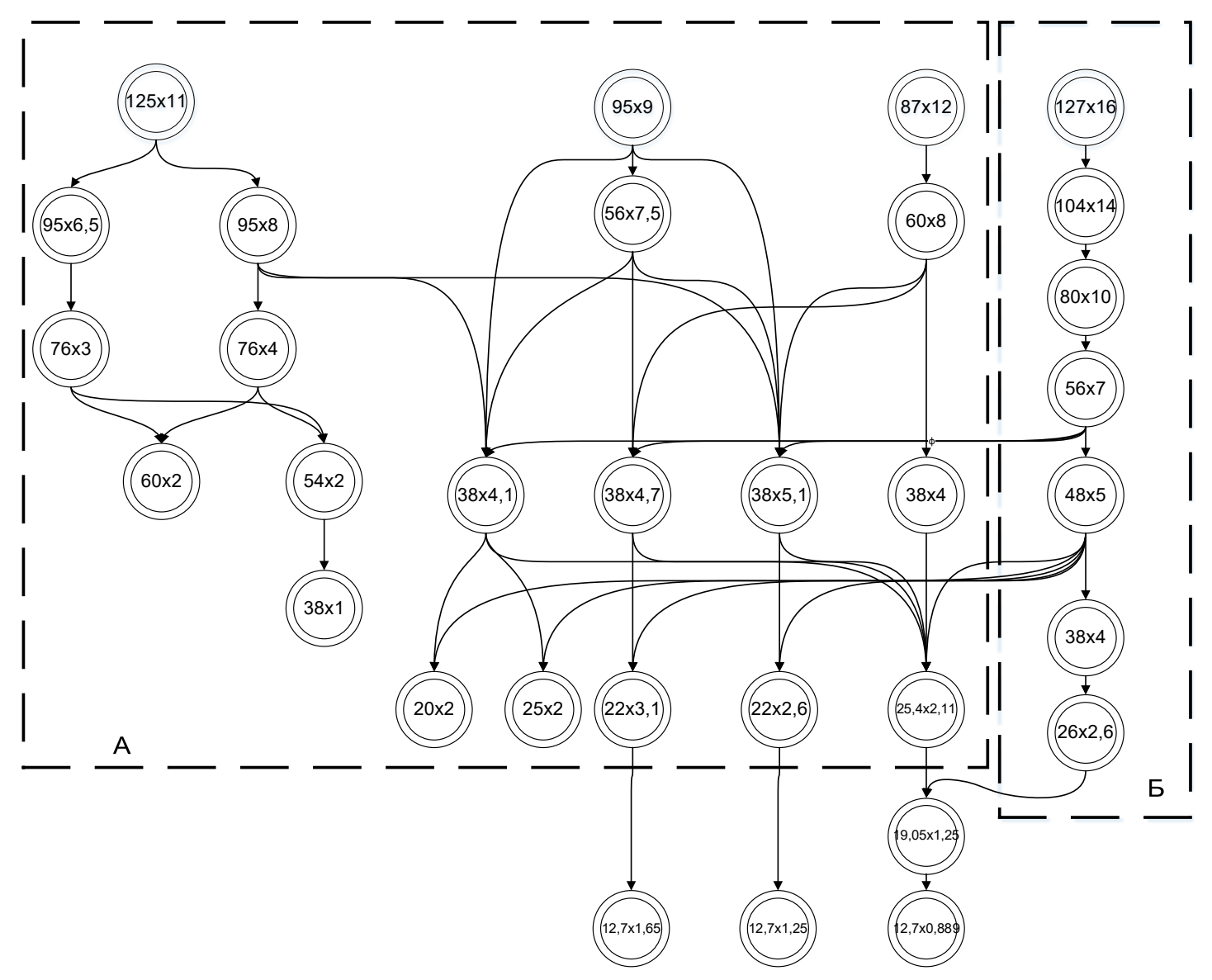

Рис. 6. Сравнение известного маршрута производства труб из сплавов на основе титана и предлагаемых: А - предлагаемые; Б - известный (общепринятый маршрут)

Для производства труб размерами 19,05 х 1,25 мм и 12,7 х 0,889 мм по общепринятым маршрутам требуется семь и восемь прокаток соответственно. РКМ при этом равен 1,61,8. По предлагаемым маршрутам - четыре и пять прокаток. РКМ ожидается на уровне 1,41,5. Рекомендуемые маршруты сокращают цикличность производства, позволяют сэкономить вспомогательные материалы и энергоносители, обеспечить требуемую точность труб (разностенность не более 0,09 мм для труб 19.05 х 1.25 мм и 0,089 мм для труб 12.7 х 0,889 мм). Сравнение величин обжатий по станам показывает, что при известных маршрутах они сильно разнятся в каждой прокатке, в первом проходе - 29,1\%, во втором - $44,4 \%$, третьем - 51,0 \%, четвертом - 37,3\%, пятом - 44,2 \%, шестом - 47,5\%, седьмом - 81,5\%, восьмом - 52,8 \%. Для рекомендованных маршрутов прокатки обжатия находятся в близком диапазоне величин от $52,8 \%$ до $67,3 \%$ (рис. 7). То есть, величины степени деформации различаются в последовательных прокатках на $\sim 14 \%$ при применении предлагаемых маршрутов и $34 \%$ при общепринятых маршрутах. Отрицательным аспектом общепринятых маршрутов является прокатка труб с весьма высокими деформациями $(70-80 \%)$, при которых основные узлы станов ХПТ работают с предельными нагрузками, и возникает опасность растрескивания концов труб.

Производственная практика показывает, что наиболее рациональными с точки зрения экономии ресурсов и максимального снижения разностенности прокатываемых труб в каждом проходе (переделе) являются маршруты прокатки, при которых суммарные обжатия за проход составляют $50-60 \%$. В этом случае без особых трудностей обеспечивается необходимый уровень механических свойств готовых труб из титановых сплавов. 


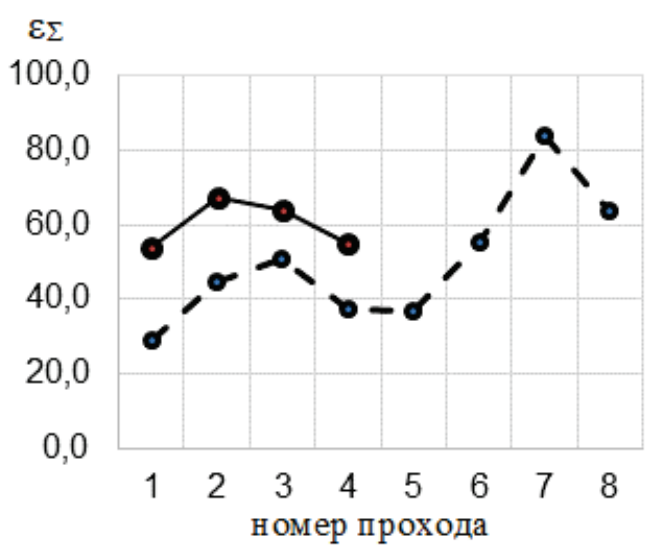

Рис. 7. Распределение обжатий по проходам при производстве труб размером 19,05 x 1,25 мм: - - общепринятый маршрут, —- тредлагаемый маршрут

Преимуществом многоцикличной прокатки принято считать способность уменьшать разностенность труб. То есть, бытует мнение, что чем больше прокатных переделов, тем точнее размеры холоднокатаных труб. Однако, выполненное в производственных условиях сравнение точности труб, изготовленных по общепринятому и предлагаемому маршрутам показывают, что трубы размерами 12,7 х 0,889 мм прокатанные по известному маршруту имели разностенность $\sim 0,125$ мм, а при использовании рекомендуемого маршрута имели разностенность $\sim 0,089$ мм. Точность труб во втором случае улучшилась на $\sim 30 \%$.

Приведенные данные являются предварительными, а сделанные выводы требуют подтверждения производственной практикой. Тем не менее, полученные результаты являются весьма обнадеживающими в плане реализации технологических решений, направленных на повышение точности холоднокатаных труб из сплавов на основе титана.

\section{Библиографический список}

1. Столетний М. Ф., Клемперт Е. Д. Точность труб. Москва : Металлургия. 1975. 239 с.

2. Данченко В. Н., Чус А. В. Продольная прокатка труб. Москва : Металлургия. 1984. 137 с.

3. Дегтярев В. С., Мацко Ю. Ю., Фролов Я. В. Уменьшение эксцентрической разностенности при холодной пильгерной прокатке труб. Металл и литье Украины. 2006. № 11-12. С. 39-41.

4. Мищенко А. В., Григоренко В. У. Экспериментальные исследования закономерностей снижения поперечной разностенности труб при холодной деформации на оправке. Обработка металлов давлением. Сборник научных трудов.
Краматорск : ДГМА. 2013. № 4(37). С. 172-176.

5. Пилипенко С.В. Исследование изменения разностенности труб в ходе прокатки на стане ХПТ. Сталь. 2016. № 3. С. 32-37.

6. Третьяков А. В., Зюзин В. И. Механические свойства металлов и сплавов при обработке давлением. Москва : Металлургия, 1973. 224 с.

7. Полухин П. И., Гун Г. Я., Галкин М. М. Сопротивление пластической деформации металлов и сплавов. Москва : Металлургия. 1976. 488 с.

8. Шевакин Ю. Ф. Калибровка и усилия при холодной прокатке труб. Москва : Металлургиздат. $1963.269 \mathrm{c}$.

9. Мищенко А. В. Состояние и тенденции развития производства холоднокатаных труб из сплавов на основе титана. Металл и литье $У_{\kappa-}$ pauны. 2019. № 3-4 (310-311). C.84-95.

\section{References}

1. Stoletniy, M. F., \& Klempert Y. D. (1975). Pipe accuracy. Moskva: Metallurgiya.

2. Danchenko, V. N., \& Chus A. V. (1984). Longitudinal rolling of pipes. Moskva: Metallurgiya.

3. Degtyarev, V. S., Matsko, Y. Y., \& Frolov, Y. V. (2006). Reduction of eccentric difference during cold pilger tube rolling. Metall $i$ lite Ukrainy, (11-12), 39-41.

4. Mishchenko, A. V., \& Grigorenko, V. U. (2013). Experimental studies of the laws governing the reduction of the lateral difference of pipes during cold deformation on the mandrel. Obrabotka metallov davleniyem. Kramatorsk: DGMA, (4), 172-176.

5. Pilipenko, S. V. (2016). The study of changes in the difference in the pipes during rolling at the CRTM. Steel, (3), 32-37.

6. Tretyakov, A. V., \& Zyuzin V. I. (1973). Mechanical properties of metals and alloys during pressure processing. Moskva: Metallurgiya.

7. Polukhin, P. I., Gun, G. Y., \& Galkin, M. M. (1976). Resistance to plastic deformation of metals and alloys. Moskva: Metallurgiya.

8. Shevakin, Y. F. (1963). Calibration and efforts during cold rolling of pipes. Moskva: Metallurgizdat.

9. Mishchenko, A. V. (2019). Status and development trends of the production of cold-rolled pipes from titanium-based alloys. Metall i lite Ukrainy, (3-4), 1-11.

Мета. Метою досліджень маршрутів виробництва і твердості труб було отримання нових науково-практичних даних про можливості зменшення поперечної разностенность хо- 
лоднокатаний труб зі сплавів на основі титану для подальших рекомендації про модернізацію марирутів прокатки труб.

Методика. Досліджено та узагальнено дані, щуо характеризують хімічний склад і механічні властивості труб, виготовлених з різних сплавів на основі титану. Для труб зі сплаву ПТ-1М проведено експеримент з дослідження твердості, щзо доповнило раніше узагальнені дані про сплави. Дослідження твердості труб виконувалося иляхом лабораторних досліджень зразків труб різної в недеформованому стані. Для побудови графіка співвідношення межі міцності $\sigma_{в}$ i твердості НВ сплавів на основі титану були використані як табличні показники, так і результати власних досліджень. Зроблено порівняння проектування маршрутів прокатки труб зі сплавів на основі титану за відомим марирутом та запропонованими.

Результати. Досліджено співвідношення межі міиностіб в $і$ твердості $(H B)$, а також побудований графік співвідношення для сплавів на основі титану, який включає дані про таких сплавах як ВТ1-00, ПТ-7М, АТ3 і ПТ-1М, ОТ4-0, ВТ9 $i$ ін. Теоретично і експериментально показано, щзо абсолютна різностінність стінки холоднокатаних труб зі сплавів на основі титану зворотньо пропориійно залежить від ступеня відносної деформацї при холодній прокатці. Порівняно підходи, щуо застосовуються для проектування маршрутів прокатки труб зі сплавів на основі титану. Прогнозування зміни різностінності з використанням розвиненого методу показало, що у нових маршрутів прогнозований рівень разностенность нижче на $30 \%$ в порівнянні з існуючим.

Наукова новизна. Доповнені дані про твердість труб, шчо виготовляються їх сплаву ПТ-1М. Розширено відомості залежності твердості труб від межі міциності для групи титанових сплавів. Наведено практичне застосування запропонованого методу прогнозування поперечної різностінності.

Практична цінність. За результатами досліджень рекомендовані підходи до вибору $i$ розробки маршрутів прокатки при виробництві холоднокатаних труб зі сплавів на основі титану, щзо забезпечують підвищення їх точності. Представлені формули, придатні для експреспрогнозу точності труб в залежності від ступеня сумарної деформації при холодній прокатці.

Ключові слова: труби, титан, сплави, хімічний склад, механічні властивості, технологія, прокатка, режими.
Purpose. The purpose of research on production routes and pipe hardness was to obtain new scientific and practical data on the possibility of reducing cross-section wall thickness variations of cold-rolled pipes made of titanium-based alloys for further recommendations on the modernization of pipe rolling routes.

Methods. Data describing the chemical composition and mechanical properties of pipes made of various titanium-based alloys have been find and generalized. For pipes made of PT-1M alloy, an experiment was made to study the hardness, which supplemented the previously generalized data on alloys. The study of the hardness of pipes was performed by laboratory studies of samples of pipes in an undeformed state. To plot the ratio of the ultimate strength $\sigma_{B}$ and the hardness $H B$ of titaniumbased alloys, tabular indicators were used, as well as the results of my own research. Comparison is made between the design of the known route and the proposed ones for rolling pipes made of titaniumbased alloys along.

Results. The ratio of the ultimate strength $\sigma_{B}$ and hardness (HB) is researched, and a graph of the ratio for titanium-based alloys is drafted, including data on such alloys as VT1-00, PT-7M, AT3 and PT-1M OT4-0, VT9, etc. Theoretically and experimentally, it is shown that the absolute thickness variation of the wall of cold-rolled pipes made of titanium-based alloys depends inversely on the degree of relative deformation during cold rolling. Approaches that use were compared to design routes for rolling pipes made of titanium alloys. Forecasting wall thickness variation changes in the difference using the developed method showed that the new routes have a predicted level of difference lower by $\sim 30 \%$ compared to the existing one.

Originality. Updated data on the hardness of pipes made of PT-1M alloy. The data on the dependence of pipe hardness on the ultimate strength for a group of titanium alloys is expanded. The practical application of the proposed method for forecasting the wall thickness variation is given.

Practical implications. Based on the results of research, approaches to the selection and development of rolling routes in the production of coldrolled pipes made of titanium-based alloys are recommended, which provide an increase in their accuracy. The presented formulas are suitable for a rapid forecast of pipes accuracy depending on the degree of total deformation during cold rolling.

Key words: pipes, titanium, alloys, chemical composition, mechanical properties, technology, rolling, modes.

Рукопис надійшов 28.11.2019 